\title{
İçmesuyu Dağıtım Sistemlerinde Arıza Bakım Onarım Süreçlerinin İzlenmesi için Performans Göstergeleri
}

\author{
Cansu Orhan ${ }^{1}$, Mahmut Fırat ${ }^{2 *}$, Salih Y1lmaz ${ }^{3}$, Abdullah Ateş ${ }^{4}$ \\ ${ }^{1}$ Ardahan Üniversitesi, Ardahan, Türkiye, (ORCID: 0000-0002-0987-1297), cansuorhan44@gmail.com \\ ${ }^{2 *}$ İnönü Üniversitesi, Malatya, Turkey, (ORCID: 0000-0002-8010-9289), mahmut.firat@,inonu.edu.tr \\ ${ }^{3}$ Çankırı Karatekin Üniversitesi, Ankara, Turkey, (ORCID: 0000-0002-3206-1225), salihymz@gmail.com \\ 2̇̇nönü Üniversitesi, Malatya, Turkey, (ORCID: 0000-0002-4236-6794), abdullah.ates@inonu.edu.tr
}

(2nd International Conference on Applied Engineering and Natural Sciences ICAENS 2022, March 10-13, 2022)

(DOI: $10.31590 /$ ejosat.1077753)

ATIF/REFERENCE: Orhan, C., Fırat, M., Yılmaz, S. \& Ateş, A. (2022). İçmesuyu Dağıtım Sistemlerinde Arıza Bakım Onarım Süreçlerinin İzlenmesi için Performans Göstergeleri. European Journal of Science and Technology, (34), 126-134.

$\ddot{O} \mathbf{z}$

İçmesuyu şebekelerinde oluşan arızalar su kesintisi, şebeke basıncının düşmesi, su kalitesinin düşmesi, su ve enerji kaybı, ekonomik kayıplar, trafik aksaklıkları, müşteri memnuniyetsizlikleri gibi sorunlara neden olmaktadır. İçmesuyu dağıtım sistemlerinde çeşitli sebeplerle meydana gelen arızaların zamanında tespit edilmesi, onarılması ve sistem bakımının yapılması su kayıp yönetimi, Su İdarelerin ekonomisi ve sürdürülebilir su tedariğinin sağlanması açısından oldukça önem arz etmektedir. Arıza bakım planlamaları rehabilitasyon ve yenileme, temizleme, bakım-onarım gibi çeşitli alternatifleri içeren karmaşık bir süreçtir. Bu çalışmanın genel amacı, içmesuyu dağıtım sistemlerinde meydana gelen arızaların performans göstergeleri ile tespit edilmesi ve arıza bakım onarım süreçlerinin izlenmesinin sağlanmasıdır. Bu amaçla çalışmada kullanılacak olan performans göstergelerinin tespiti için öncelikle literatür taraması yapılmış ve çeşitli kurumlar tarafından arıza yönetimi için önerilen performans göstergeleri elde edilmiş ve çalışma kapsamında çeşitli sorunların çözümü için performans göstergesi önerileri sunulmuştur. Belirlenen 18 gösterge, zorluk düzeyleri, gereksinimleri ve veri yapısı dikkate alınarak temel, orta ve ileri seviye şeklinde gruplandırılmıştır. Çalışma performans göstergelerinin belirlenmesi, göstergeler için gerekli verilerin elde edilmesi, analizin yapılması ve değerlendirme aşamalarından oluşmaktadır. Çalışma sonucunda hesaplanan göstergelerin arıza performansının izlenmesinde referans bilgi ürettiği ve arızaların azaltılmasında uygulanan yöntemlerden elde edilen kazanımların analiz edilmesinde de bu göstergelerin önemli faydalar sağladığı görülmüştür.

Anahtar Kelimeler: Içme Suyu Dağıtım Sistemleri, Arıza, Arıza Oranı, Performans Göstergeleri.

\section{Performance Indicators for Monitoring Failure Maintenance and Repair Processes in Water Distribution Systems}

\begin{abstract}
Failures in water networks cause problems such as water interruptions, decrease in network pressure, decrease in water quality, loss of water and energy, economic losses, traffic disruptions, and customer dissatisfaction. Detection, repair and system maintenance of failures due to various reasons are very important in terms of water loss management, economy of Water Administrations and ensuring sustainable water supply. Failure maintenance planning is a complex process that includes various alternatives such as rehabilitation and renewal, cleaning, maintenance-repair. The general purpose of this study is to detect the failures in water distribution systems with performance indicators and to monitor the breakdown maintenance and repair processes. For this purpose, in order to determine the performance indicators to be used in the study, first of all, a literature review was made and the performance indicators recommended for failure management by various institutions were obtained and performance indicator suggestions were presented for the solution of various problems within the scope of the study. A total of 18 indicators determined are grouped as basic, intermediate and advanced, taking into account their difficulty levels, needs and data structure. The study consists of the stages of determining the performance indicators, obtaining the necessary data for the indicators, performing the analysis and evaluation.. I was seen that the calculated indicators produce reference information in monitoring the failure performance and these indicators provide significant benefits in analyzing the gains obtained from the methods applied in reducing the failures.
\end{abstract}

Keywords: Water Distribution Systems, Failure, Failure Rate, Performance Indicators. 


\section{Giriş}

Dağıtım sistemlerinde çeşitli faktörlere (çevresel, hidrolik, işletme, tasarım, şebeke fiziksel) bağlı olarak arızalar meydana gelmektedir (Pearson, 2019). Arıza sayısının artmasına bağlı olarak işletme maliyeti artmakta, şebeke işletme koşulları bozulmakta ve hizmet kalitesi düşmektedir. $\mathrm{Bu}$ nedenle bu arızaların azaltılması ve önlenmesi sistem verimliliğinin iyileştirilmesi açısından oldukça önemlidir. Ancak bunu gerçekleştirmek için öncelikle meydana gelen arızaların uygun, ölçülebilir ve uygulanabilir göstergelere göre analiz edilmesi ve izlenmesi gerekir (Dighade vd., 2014; Liemberger ve Farley 2004; Moslehi, Jalili-Ghazizadeh, and Yousefi-Khoshqalb 2021; Berardi and Giustolisi 2021; Marzola vd., 2021)

Literatürde arızaların ve sızıntıların yönetilmesi (tespit, önleme, azaltma, kontrol) amaciyla, izole alt ölçüm bölgelerinin oluşturulması ve yönetilmesi (Diano vd., 2013; Mutikanga vd., 2013; Vicente vd., 2016; Karathanasi ve Papageorgakopoulos, 2016; Laucelli vd., 2017; Salomons vd., 2017), basınç kontrol yönetiminin uygulanması (Roshani ve Filion, 2014; Lima vd., 2018; Carmona-Paredes ve Carmona-Benítez, 2018; Fontana vd., 2018), ekonomik ömrünü doldurmuş ve rehabilitasyonda öncelikli bölgelerin belirlenmesi (Nafi vd., 2008; Rogers ve Grigg, 2009; Graaf ve Brugge, 2010; Tee vd., 2014), arıza tahmin modellerinin geliştirilmesi (Pietrucha-urbanik, 2015; Chik vd., 2017; Kutyłowska, 2017; Xu vd., 2018), otomasyon ve yönetim sistemlerinin kullanılması (Eugine, 2017; Farah vd., 2017; Jadhao vd., 2018; Wu vd., 2018) gibi çeşitli yöntem ve araçlar kullanılmaktadır.

Dighade vd., 2014, gelişmekte olan ülkelerde su dağıtım sistemlerinde karşılaşılan sorunların çözümü için uygulanabilir ve ulaşılabilir bir arıza yönetim stratejisinin geliştirilmesi gerektiği vurgulanmıştır. Liemberger ve Farley 2004, gelir getirmeyen su azaltma stratejisi kapsamında kullanılacak olan verilerin sahadan elde edilmesi ve ulaşılamayan veriler için ise tahmin yöntemlerinin yürütülmesi ve veri doğruluğunun arttırılması amaçlanmıştır.

Seago vd., 2007, Her su dağıtım sisteminde kullanım ömrü boyunca bazı arızalar meydana gelebilmektedir. Bu arızalardan kaynaklanan sızıntıların belirlenmesi ve karşılaştırılabilir gerçekçi bir çözüm oluşturulabilmesi önemlidir. Cullinane 1986, bir su dağıtım sistemi suyun dağıtılmasında kullanılan borular, basıncı düzenleyen pompalar, suyu depolayan hazneler gibi mekanik, hidrolik ve elektromanyetik bileşenlerden oluşmaktadır. Su dağıtım sisteminin herhangi bir noktasında meydana gelen arıza tüm sistemi etkileyebilmektedir.

Gheisi vd., 2016, su dağıtım sistemlerinde sık karşılaşılan arıza türleri mekanik, hidrolik, su kalitesi veya güvenlik açı̆̆1 nedenleriyle meydana gelmektedir. Çalışmada arıza türüne yönelik çözüm önerileri tartışılmıştır. Haider vd., 2015, kaynak yetersizliği, ekonomik sorunlar ve veri kısıtlamaları nedeniyle kıyaslanamayan küçük ve orta ölçekli su hizmetlerinin performans indisleri kullanılarak kıyaslanması amacıyla bir yaklaşım önerilmiştir. Neamtu 2011, su kayıplarını kontrol etmek, sistemin teknik ve ekonomik performansını belirleyerek su kayıp oranını düşürmek amacıyla altyapı kaçak endeksi, cari yıllık gerçek kayıp, yıllık kaçınılmaz gerçek kayıp, ekonomik kaçak endeksi göstergelerini kullanan bir strateji geliştirilmiştir.

$\mathrm{Bu}$ çalışmada, içmesuyu dağıtım sistemlerinde meydana gelen arızaların performans göstergeleri ile analiz edilmesi ve izlenmesi amaçlanmıştır. $\mathrm{Bu}$ amaçla toplamda 18 adet gösterge dikkate alınmıştır. $\mathrm{Bu}$ göstergelerin belli bir kısmı literatürde çeşitli kurumlar tarafından önerilen göstergeleri içermektedir. Belli bir kısmı ise bu çalışma kapsamında önerilmiştir. Bu göstergelerin kullanılması ile dağıtım sistemlerinin arıza yönetim performansının analizi ve değişiminin izlenmesi mümkün olmaktadir.

\section{Materyal ve Yöntem}

$\mathrm{Bu}$ çalışmada içme suyu dağıtım sistemlerinin arıza performansının analiz edilmesi ve izlenmesi amaçlanmıştır. $\mathrm{Bu}$ kapsamda toplamda 18 göstergeden oluşan bir arıza yönetimi performans değerlendirme sistemi oluşturulmuştur. $\mathrm{Bu}$ göstergelerin belli bir kısmı çeşitli kurumlardan (Uluslararası Su Birliği, IWA) tarafından önerilen göstergeleri içerirken belli bir kısmı ise bu çalışma kapsamında önerilmiştir. Bu göstergeler, veri ölçüm zorluğu, gereksinimleri ve uygulama zorlukları esas alınarak "temel seviye (Çizelge 1)", "orta seviye (Çizelge 2)" ve “ileri seviye (Çizelge 3)" olmak üzere üç sınıfa ayrılmıştır.

Temel seviye göstergelerde genel olarak yüzeye çıkan (rapor edilen) arızalar şebeke ana hat uzunluğuna ve servis bağlantı sayısına göre analiz edilmektedir. Rapor edilen arızalar, yüzeye çıkmakta, çağrı merkezine bildirilmekte ve onarılmaktadır. Bu arızalarla mücadelede çağrı merkezinin aktif kullanılması, arıza onarım ekibinin yeterli olması gerekir. $\mathrm{Bu}$ arıza sayısının ve onarım süresinin azaltılması gerekmektedir. $\mathrm{Bu}$ faaliyetler idarenin en temel yapması gereken süreçler olduğu için verileri daha düzenli tutulmaktadır. $\mathrm{Bu}$ nedenle bu göstergeler temel seviye sınıfına eklenmiştir. 
Çizelge 1. Temel Seviye Performans Göstergeleri

\begin{tabular}{|c|c|c|c|}
\hline Kodu & Gösterge Adı & Birim & Gösterge Açıklama \\
\hline PG1 & $\begin{array}{l}\text { Toplam rapor edilen } \\
\text { arıza oranı }\end{array}$ & $\begin{array}{l}\text { arıza/şebeke } \\
\text { uzunluğu } \\
(100 \mathrm{~km}) / \mathrm{y} 11\end{array}$ & $\begin{array}{l}\text { Bu gösterge } 100 \mathrm{~km} \text { şebeke ana hat uzunluğu başına düşen toplam rapor edilen arıza } \\
\text { sayısını ifade eder. Bu gösterge bölgesel olarak arıza yoğunluğunun analizinde } \\
\text { kullanılır ve yıllık hesaplanır. Bunun için verilerin düzenli tutulduğu bir arıza } \\
\text { yönetim sistemi ve CBS olmalıdır. }\end{array}$ \\
\hline PG2 & $\begin{array}{l}\text { Rapor edilen şebeke } \\
\text { arıza oranı (IWA } \\
\text { Op31) }\end{array}$ & $\begin{array}{l}\text { arıza/şebeke } \\
\text { uzunluğu } \\
(100 \mathrm{~km}) / \mathrm{y} 1 \mathrm{l}\end{array}$ & $\begin{array}{l}\text { Bu gösterge } 100 \mathrm{~km} \text { şebeke ana hat uzunluğu başına düşen şebeke ana hat rapor } \\
\text { edilen arıza sayısını ifade eder. Bu gösterge bölgesel olarak arıza yoğunluğunun } \\
\text { analizinde kullanılır ve yıllık hesaplanır. Bunun için verilerin düzenli tutulduğu bir } \\
\text { arıza yönetim sistemi ve CBS olmalıdır. }\end{array}$ \\
\hline PG3 & $\begin{array}{l}\text { Rapor edilen servis } \\
\text { bağlantı arıa oran1 } \\
\text { (IWA Op32) }\end{array}$ & $\begin{array}{l}\text { arıza/şebeke } \\
\text { uzunluğu } \\
(100 \mathrm{~km}) / \mathrm{y} 11\end{array}$ & $\begin{array}{l}\text { Bu gösterge } 100 \mathrm{~km} \text { şebeke ana hat uzunluğu başına düşen servis bağlantı rapor } \\
\text { edilen arıza sayısını ifade eder. Bu gösterge bölgesel olarak arıza yoğunluğunun } \\
\text { analizinde kullanılır ve yıllık hesaplanır. Bunun için verilerin düzenli tutulduğu bir } \\
\text { arıza yönetim sistemi ve CBS olmalıdır. }\end{array}$ \\
\hline PG4 & $\begin{array}{l}\text { Rapor edilen servis } \\
\text { bağlantı arıa oranı } \\
\text { (IWA Op32) }\end{array}$ & $\begin{array}{l}\text { arıza/servis } \\
\text { bağlantı } \\
(1000) / y 11\end{array}$ & $\begin{array}{l}\text { Bu gösterge } 1000 \text { servis bağlantı başına düşen servis bağlantı rapor edilen arıza } \\
\text { sayısını ifade eder. Bu gösterge bölgesel olarak arıza yoğunluğunun analizinde } \\
\text { kullanılır ve yıllık hesaplanır. Bunun için verilerin düzenli tutulduğu bir arıza } \\
\text { yönetim sistemi ve CBS olmalıdır. }\end{array}$ \\
\hline PG5 & $\begin{array}{lr}\text { Rapor } & \text { edilen } \\
\text { arızalara } & \text { müdahale } \\
\text { verimliği } & \end{array}$ & $\%$ & $\begin{array}{l}\text { Bu gösterge dağıtım sisteminde tamiri yapılan arızaların toplam arıza içindeki } \\
\text { oranını ifade eder. } \mathrm{Bu} \text { gösterge özellikle idarede arıza onarım ekibinin } \\
\text { performansının izlenmesinde (genelde yıllık) kullanılır. Bu gösterge için arıza } \\
\text { yönetim sisteminde verilerin düzenli tutulması gerekir. }\end{array}$ \\
\hline PG6 & $\begin{array}{l}\text { Arıza müdahale } \\
\text { süresi }\end{array}$ & saat & $\begin{array}{l}\text { Bu gösterge idarede rapor edilen arızalara müdahale süresini ifade eder. Arıza } \\
\text { müdahale süresi uzadıkça sızıntı hacmi artacaktır. Bu gösterge için arıza yönetim } \\
\text { sisteminde verilerin düzenli tutulması gerekir. } \mathrm{Bu} \text { gösterge işletme yönetimi } \\
\text { açısından önemli olup aylık izlenmelidir. }\end{array}$ \\
\hline
\end{tabular}

Çizelge 2. Orta Seviye Performans Göstergeleri

\begin{tabular}{|c|c|c|c|}
\hline odu $^{K}$ & Gösterge Adı & Birim & Gösterge Açıklama \\
\hline PG7 & $\begin{array}{l}\text { Şebeke veri } \\
\text { doğrulama oranı }\end{array}$ & $\%$ & $\begin{array}{l}\text { Bu gösterge verisi sahada doğrulanmış ve CBS veri tabanında güncel olan şebeke } \\
\text { oranını (\% } 100 \text { 'e yakın olması gerekir) ifade eder. Bu gösterge aylık/yıllık analiz } \\
\text { edilir ancak yıllık olarak değerlendirilir. }\end{array}$ \\
\hline \multirow[t]{2}{*}{ PG8 } & $\begin{array}{l}\text { Vana Yoğunluğu } \\
\text { (IWA PH8) }\end{array}$ & $\begin{array}{l}\text { vana/şebeke } \\
\text { uzunluğu(100 } \\
\mathrm{km}) / \mathrm{y} 1 \mathrm{l}\end{array}$ & $\begin{array}{l}\text { Bu gösterge verisi sahada doğrulanmış ve CBS veri tabanında güncel olan ve birim } \\
\text { şebeke ana hat uzunluğu başına düşen vana oranını verir. Bu gösterge aylık veya } \\
\text { y1llık olarak analiz edilmeli ve izlenmelidir. Bu gösterge için güncel CBS şebeke ve } \\
\text { vana veri tabanının olması gerekir. }\end{array}$ \\
\hline & $\begin{array}{l}\text { Vana Yoğunluğu } \\
\text { (IWA PH8) }\end{array}$ & $\%$ & $\begin{array}{l}\text { Bu gösterge verisi sahada doğrulanmış ve CBS veri tabanında güncel vana oranını } \\
(\% 100 \text { 'e yakın olmalı) verir. Şebekenin yönetilmesinde vanalar kritik öneme } \\
\text { sahiptir. Bu gösterge aylık veya yıllık analiz edilmelidir. }\end{array}$ \\
\hline PG9 & $\begin{array}{ll}\text { Vana } & \text { arıza } \\
\text { yoğunluğu }\end{array}$ & $\%$ & $\begin{array}{l}\text { Bu gösterge şebekedeki vana başına düşen arıza sayısını ifade eder. Bu gösterge } \\
\text { bölgesel olarak arıza yoğunluğunun analizinde ve izlenmesinde kullanılır. Bu } \\
\text { gösterge yıllık hesaplanır. Bunun için verilerin düzenli tutulduğu bir arıza yönetim } \\
\text { sistemi olmalı ve CBS vana veri tabanı güncel olmalıdır. Bu gösterge yıllık olarak } \\
\text { izlenmelidir. }\end{array}$ \\
\hline PG10 & Vana bakım oranı & $\%$ & $\begin{array}{l}\text { Bu gösterge sistemde vana sayısı başına yapılan denetim sayısını ifade eder. Bu } \\
\text { gösterge özellikle şebeke yönetiminde kritik öneme sahip olan vanaların düzenli } \\
\text { çalışması için önemlidir. Bunun için verilerin düzenli tutulduğu bir vana yönetim } \\
\text { sisteminin olması ve CBS vana veri tabanında güncel olması gerekir. Bu gösterge } \\
\text { yıllık olarak izlenmelidir. }\end{array}$ \\
\hline PG11 & Vana Değişim oranı & $\%$ & $\begin{array}{l}\text { Bu gösterge sistemde vana sayısı başına değiştirilen vana sayısını ifade eder. Bu } \\
\text { gösterge konumsal ve zamansal olarak değiştirilen vanaların izlenmesi, bakım ve } \\
\text { denetim planlarının oluşturulması ve vana yönetimi için önemlidir. Bunun için } \\
\text { verilerin düzenli tutulduğu bir vana yönetim sisteminin olması ve CBS vana veri } \\
\text { tabanında güncel olması gerekir. Bu gösterge yıllık olarak izlenmelidir. }\end{array}$ \\
\hline PG12 & $\begin{array}{l}\text { Yenilenen bölge } \\
\text { arıza oranı }\end{array}$ & $\%$ & $\begin{array}{l}\text { Bu gösterge şebeke yenilenen bölgede yenileme verimliliğinin izlenmesinde } \\
\text { kullanılır. Bu gösterge yıllık hesaplanır. Bu gösterge için iyi çalışan ve verilerin } \\
\text { düzenli tutulduğu bir arıza yönetim sisteminin olması ve CBS şebeke veri tabanının } \\
\text { güncel olması gerekir. Bu gösterge aylık veya yıllık olarak analiz edilmeli ancak } \\
\text { y1llık olarak değerlendirilmelidir. }\end{array}$ \\
\hline
\end{tabular}


Çizelge 2 incelendiğinde, genel olarak şebeke elemanlarının bakım onarım ve değişim süreçlerinin izlenmesi amaçlanmaktadır. Bu süreçler genel olarak zaman alıcı, maliyetli ve oldukça fazla gereksinimlere sahiptir. $\mathrm{Bu}$ nedenle bu göstergelerin zorluk düzeyi dikkate alınarak orta seviye uygulamalara eklenmiştir. Vanalar, dağıtım sistemlerinde, işletme koşullarının sağlanması, arızaların yönetilmesi ve onarılması, hidrolik parametrelerin (debi ve basınç) düzenlenmesinde kullanılmaktadır. $\mathrm{Bu}$ elemanların yerinin bilinmesi, bakım programının oluşturulması, düzenli izlenmesi, sürekli arıza oluşturanların yenilenmesi gibi süreçlerin izlenmesi gerekir. Çizelge 2'de verilen göstergeler temel olarak bu süreçlerin izlenmesi kapsamında teknik personeller için referans oluşturmaktadır.

Çizelge 3'te verilen göstergeler bir idarede/sistemde ileri seviye uygulamaları içermektedir. Bu göstergelerin hesaplanmasında kullanılan rapor edilmeyen (yüzeye çıkmayan) arızaların elde edilmesi için idarede aktif sızıntı kontrolünün uygulanması gerekir. $\mathrm{Bu}$ yöntem dağıtım sistemlerinde yüzeye çıkmayan arızaların tespit edilmesi ve onarılması için uygulanan, izole ölçüm bölgelerinin planlanması, minimum gece debisinin analizi ve akustik ekipmanlarla sizıntı yerinin tespiti faaliyetlerinin yapılması gerekir. Bunların yapılması için, kurumsal ve personel deneyiminin yeterli olması, teknik alt yapının uygun olması ve farkındalığın olması gerekir. Bu nedenle bu göstergeler ileri seviye uygulamalar sınıfına eklenmiştir. 
Çizelge 3. Illeri Seviye Performans Göstergeleri

\begin{tabular}{|c|c|c|c|}
\hline Kodu & Gösterge Adı & Birim & Gösterge Açıklama \\
\hline PG13 & $\begin{array}{l}\text { Şebeke Arıza sıklık } \\
\text { indeksi }\end{array}$ & birimsiz & $\begin{array}{l}\text { Bu gösterge şebekedeki arıza oranının uluslararası literatürde önerilen sınır } \\
\text { değerlere göre kıyaslanmasını sağlar. Bu göstergenin 1'e yakın olması sistemin iyi } \\
\text { bir davranış gösterdiğini ifade eder. Özellikle konumsal olarak değişimlerin } \\
\text { izlenmesi ve şebeke yenilemeye karar vermede referans alınabilir. Bu gösterge için } \\
\text { verilerin düzenli tutulduğu bir arıza yönetim sisteminin olması ve şebeke } \\
\text { uzunluğunun CBS veri tabanında güncel olması gerekir. Bu gösterge yıllık olarak } \\
\text { analiz edilmeli ve izlenmelidir. }\end{array}$ \\
\hline PG14 & $\begin{array}{l}\text { Servis Bağlantı } \\
\text { Arıza sıklık indeksi }\end{array}$ & birimsiz & $\begin{array}{l}\text { Bu gösterge şebekedeki arıza oranının uluslararası literatürde önerilen sınır } \\
\text { değerlere göre kıyaslanmasını sağlar. Bu göstergenin 1'e yakın olması sistemin iyi } \\
\text { bir davranış gösterdiğini ifade eder. Özellikle konumsal olarak değişimlerin } \\
\text { izlenmesi ve şebeke yenilemeye karar vermede referans alınabilir. Bu gösterge için } \\
\text { verilerin düzenli tutulduğu bir arıza yönetim sisteminin olması ve şebeke } \\
\text { uzunluğunun CBS veri tabanında güncel olması gerekir. Bu gösterge yıllık olarak } \\
\text { analiz edilmeli ve izlenmelidir. }\end{array}$ \\
\hline PG15 & $\begin{array}{l}\text { Servis bağlantı } \\
\text { yenileme oranı }\end{array}$ & $\%$ & $\begin{array}{l}\text { Bu gösterge servis bağlantı başına yenilenen servis bağlantı sayısını ifade eder. } \\
\text { Özellikle arızaların önemli bir kısmı servis bağlantılarında meydana geldiği için bu } \\
\text { gösterge yenileme verimliliğini ve arıza üzerindeki etkisini izlemede önemlidir. } \\
\text { Bunun için güncel CBS veri tabanına ihtiyaç vardır. Bu gösterge yıllık olarak analiz } \\
\text { edilmeli ve izlenmelidir. }\end{array}$ \\
\hline PG16 & $\begin{array}{l}\text { Servis bağlantı } \\
\text { verimliliği }\end{array}$ & $\%$ & $\begin{array}{l}\text { Bu gösterge yenilenen servis bağlantı başına idare tarafından yenilenen servis } \\
\text { bağlantı sayısını ifade eder. Özellikle arızaların önemli bir kısmı servis } \\
\text { bağlantılarında meydana geldiği için bu gösterge yenileme verimliliğini ve arıza } \\
\text { üzerindeki etkisini izlemede önemlidir. Güncel CBS veri tabanına ihtiyaç vardır. Bu } \\
\text { gösterge yıllık analiz edilmelidir. }\end{array}$ \\
\hline PG17 & $\begin{array}{l}\text { Rapor edilmeyen } \\
\text { servis bağlantı arıza } \\
\text { oranı }\end{array}$ & $\begin{array}{l}\text { arıza/şebeke } \\
\text { uzunluğu } \\
(100 \mathrm{~km}) / \mathrm{y} 1 \mathrm{l}\end{array}$ & $\begin{array}{l}\text { Bu gösterge birim şebeke ana hat uzunluğu başına düşen toplam rapor edilmeyen } \\
\text { servis bağlantı arıza sayısını ifade eder. Bu gösterge bölgesel olarak arıza } \\
\text { yoğunluğunun analizinde ve izlenmesinde kullanılır. Özellikle konumsal olarak } \\
\text { değişimlerin izlenmesi ve şebeke yenilemeye karar vermede referans alınabilir. Bu } \\
\text { gösterge yıllık hesaplanır. Bu gösterge için iyi çalışan ve verilerin düzenli tutulduğu } \\
\text { bir arıza yönetim sisteminin olması ve şebeke uzunluğunun CBS veri tabanında } \\
\text { güncel olması gerekir. }\end{array}$ \\
\hline PG18 & $\begin{array}{l}\text { Rapor edilmeyen } \\
\text { şebeke arıza oranı }\end{array}$ & $\begin{array}{c}\text { arıza/şebeke } \\
\text { uzunluğu } \\
(100 \mathrm{~km}) / \mathrm{y} 1 \mathrm{l}\end{array}$ & $\begin{array}{l}\text { Bu gösterge birim şebeke ana hat uzunluğu başına düşen toplam rapor edilmeyen } \\
\text { şebeke arıza sayısını ifade eder. Bu gösterge bölgesel olarak arıza yoğunluğunun } \\
\text { analizinde ve izlenmesinde kullanılır. Özellikle konumsal olarak değişimlerin } \\
\text { izlenmesi ve şebeke yenilemeye karar vermede referans alınabilir. Bu gösterge yıllık } \\
\text { hesaplanır. Bu gösterge için iyi çalışan ve verilerin düzenli tutulduğu bir arıa } \\
\text { yönetim sisteminin olması ve şebeke uzunluğunun CBS veri tabanında güncel } \\
\text { olması gerekir. }\end{array}$ \\
\hline
\end{tabular}

Çizelge 4. Performans Göstergeleri ve Kullanılan Veriler

\begin{tabular}{|c|c|c|c|}
\hline Kodu & Birim & Gösterge Hesabı & Veri Adı (Kodu) \\
\hline PG1 & $\begin{array}{c}\text { arıza/şebeke uzunluğu } \\
(100 \mathrm{~km}) / \mathrm{y} 1 \mathrm{l}\end{array}$ & $(\mathrm{V} 1 / \mathrm{V} 2) * 100$ & $\begin{array}{l}\text { Toplam rapor edilen Arıza sayısı (V1) (adet) } \\
\text { Şebeke Uzunluğu (V2) (km) }\end{array}$ \\
\hline PG2 & $\begin{array}{c}\text { arıza/şebeke uzunluğu } \\
(100 \mathrm{~km}) / \mathrm{y} 11\end{array}$ & $(\mathrm{~V} 3 / \mathrm{V} 2) * 100$ & $\begin{array}{l}\text { Rapor edilen şebeke Arıza sayısı (V3) (adet) } \\
\text { Şebeke Uzunluğu (V2) (km) }\end{array}$ \\
\hline PG3 & $\begin{array}{c}\text { arıza/şebeke uzunluğu } \\
(100 \mathrm{~km}) / \mathrm{y} 1 \mathrm{l}\end{array}$ & $(\mathrm{V} 4 / \mathrm{V} 2) * 100$ & $\begin{array}{l}\text { Rapor edilen Servis Bağlantı Arıza sayısı (V4) (adet) } \\
\text { Şebeke Uzunluğu (V2) (km) }\end{array}$ \\
\hline PG4 & $\begin{array}{l}\text { arıza/servis bağlantı } \\
(1000) / \mathrm{y} 1 \mathrm{l}\end{array}$ & $(\mathrm{V} 4 / \mathrm{V} 5)^{*} 1000$ & $\begin{array}{l}\text { Rapor edilen Servis Bağlantı Arıza sayısı (V4) (adet) } \\
\text { Servis Bağlantı Sayısı (V5) (adet) }\end{array}$ \\
\hline PG5 & $\%$ & $(\mathrm{~V} 6 / \mathrm{V} 1)^{*} 100$ & $\begin{array}{l}\text { Tamiri yapılan rapor edilen arıza sayıs1 (V6) (adet) } \\
\text { Toplam Rapor Edilen Arıza sayıs1 (V1) (adet) }\end{array}$ \\
\hline PG6 & saat & V19 & Rapor edilen arızalara müdahale süresi (saat) (V19) (saat) \\
\hline PG7 & $\%$ & $(\mathrm{~V} 7 / \mathrm{V} 2) * 100$ & $\begin{array}{l}\text { Verisi Doğrulanmış CBS Veri Tabanı olan şebeke uzunluğu (km) } \\
\text { (V7) }(\mathrm{km}) \\
\text { Şebeke Uzunluğu }(\mathrm{V} 2)(\mathrm{km})\end{array}$ \\
\hline \multirow[t]{2}{*}{ PG8 } & $\begin{array}{c}\text { vana/şebeke } \\
\text { uzunluğu(100km)/y1 }\end{array}$ & $\mathrm{V} 8 / \mathrm{V} 2 * 100$ & $\begin{array}{l}\text { CBS veritabanı olan ve yeri bilinen vana Sayısı (V8) (adet) } \\
\text { Şebeke Uzunluğu (V2) }(\mathrm{km})\end{array}$ \\
\hline & $\%$ & $(\mathrm{~V} 8 / \mathrm{V} 9) * 100$ & $\begin{array}{l}\text { CBS veritabanı olan ve yeri bilinen vana Sayıs1 (V8) (adet) } \\
\text { Toplam vana sayıs1 (V9) (adet) }\end{array}$ \\
\hline PG9 & $\%$ & V10/V8*100 & $\begin{array}{l}\text { Vana arıza sayı1 (V10) (adet) } \\
\text { CBS veritabanı olan ve yeri bilinen vana Sayıs1 (V8) (adet) }\end{array}$ \\
\hline PG10 & $\%$ & $(\mathrm{~V} 11 / \mathrm{V} 8)^{*} 100$ & $\begin{array}{l}\text { Bakım-denetim yapılan vana sayıs1 (V11) (adet) } \\
\text { CBS veritabanı olan ve yeri bilinen vana Sayıs1 (V8) (adet) }\end{array}$ \\
\hline PG11 & $\%$ & $(\mathrm{~V} 12 / \mathrm{V} 8)^{*} 100$ & $\begin{array}{l}\text { Değiştirilen vana sayısı (V12 ) (adet) } \\
\text { CBS veritabanı olan ve yeri bilinen vana Sayısı (V8) (adet) }\end{array}$ \\
\hline
\end{tabular}




\begin{tabular}{|c|c|c|c|}
\hline PG12 & $\%$ & $(\mathrm{~V} 13 / \mathrm{V} 14)^{*} 100$ & $\begin{array}{l}\text { şebeke yenilenen bölgede arıza sayısı (V13) (adet) } \\
\text { şebeke yenilemeden önceki arıza sayısı (V14) (adet) }\end{array}$ \\
\hline PG13 & birimsiz & $\begin{array}{l}\left(((\mathrm{V} 3+\mathrm{V} 15) / \mathrm{V} 2)^{*} 1\right. \\
00) / 13\end{array}$ & $\begin{array}{l}\text { Rapor edilen Şebeke Arıza sayısı (V3) (adet) } \\
\text { Rapor Edilmeyen Şebeke Arıza sayısı (V15) (adet) } \\
\text { Şebeke Uzunluğu (V2) (km) } \\
\text { Şebeke arıza referans değer (13/100km) }\end{array}$ \\
\hline PG14 & birimsiz & $\begin{array}{l}\left(((\mathrm{V} 4+\mathrm{V} 16) / \mathrm{V} 5)^{*} 1\right. \\
000) / 3\end{array}$ & $\begin{array}{l}\text { Rapor edilen Servis Bağlantı Arıza sayısı (V4) (adet) } \\
\text { Rapor Edilmeyen Servis Bağlantı Arıza sayısı (V16) (adet) } \\
\text { Servis bağlantı sayısı (V5) (adet) } \\
\text { Servis bağlantı referans arıza değeri (3/1000 bağlantı) }\end{array}$ \\
\hline PG15 & $\%$ & $(\mathrm{~V} 17 / \mathrm{V} 5) * 100$ & $\begin{array}{l}\text { Yenilenen (yeni yapılan) servis bağlantı sayısı (V17) (adet) } \\
\text { Servis Bağlantı Sayısı (V5) (adet) }\end{array}$ \\
\hline PG16 & $\%$ & $(\mathrm{~V} 18 / \mathrm{V} 17) * 100$ & $\begin{array}{l}\text { İdare tarafından yapılan servis bağlantı sayısı (V18) (adet) } \\
\text { Yenilenen (yeni yapılan) servis bağlantı sayısı (V17) (adet) }\end{array}$ \\
\hline PG17 & $\begin{array}{l}\text { arıza/şebeke uzunluğu } \\
(100 \mathrm{~km}) / \mathrm{y} 1 \mathrm{l}\end{array}$ & $\mathrm{V} 16 / \mathrm{V} 2 * 100$ & $\begin{array}{l}\text { Rapor edilmeyen Servis Bağlantı Arıza sayısı (V16) (adet) } \\
\text { Şebeke uzunluğu (V2) (km) }\end{array}$ \\
\hline PG18 & $\begin{array}{l}\text { arıza/şebeke uzunluğu } \\
(100 \mathrm{~km}) / \mathrm{y} 1 \mathrm{l}\end{array}$ & $\mathrm{V} 15 / \mathrm{V} 2 * 100$ & $\begin{array}{l}\text { Rapor Edilmeyen Şebeke arıza sayısı (V15) (adet) } \\
\text { Şebeke uzunluğu (V2) (adet) }\end{array}$ \\
\hline
\end{tabular}

Çizelge 4'te verilen göstergelerin doğru ve sistematik bir şekilde hesaplanabilmesi için dağıtım sisteminde verilerin düzenli tutulması oldukça önemlidir. $\mathrm{Bu}$ nedenle idarede temel olarak aşağıda verilen çalışmaların yapılması ve izleme sistemlerinin kullanılması gerekir;

- CBS şebeke ve servis bağlantı veri tabanının oluşturulması ve sistematik olarak güncellenmesi

- CBS vana veri tabanının oluşturulması ve sistematik güncellenmesi

- Çağrı merkezi ve arıza yönetim sisteminin olması ve verilerin düzenli tutulması

- Yıllık bakım onarım programının oluşturulması, CBS ile izlenmesi ve verilerin tutulmasi

- Rapor edilmeyen sızıntılar için aktif sızıntı kontrolünün uygulanması

- Performans izleme ve analiz sisteminin oluşturulması

\section{- 3. Araştırma Sonuçları ve Tartışma}

- Çalışma kapsamında Çizelge 4'te verilen göstergeler için pilot idareler ait veri setleri için uygulama yapılmıştır (Çizelge 5). Önceki bölümde de bahsedildiği gibi göstergelerin doğru bir şekilde hesaplanması için verilerin düzenli ölçülmesi esastır. Çizelgede koyu renk ile gösterilen ve 0 (sıfır) yazılan

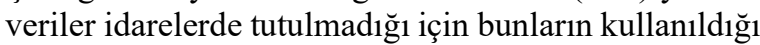
performans göstergeleri hesaplanmamıştır. Çizelge 5 'ta gösterilen veriler kullanılarak performans göstergeleri hesaplanmıştır (Çizelge 6). 
Çizelge 5. Pilot Sistemlere ait Veriler

\begin{tabular}{|c|l|c|c|c|}
\hline Veri Kodu & \multicolumn{1}{|c|}{ Arıza Bakım Onarım } & Birim & Sistem 1 & Sistem 2 \\
\hline V1 & Toplam Rapor Edilen Arıza sayısı (adet) & adet & 9,264 & 10,500 \\
\hline V2 & Şebeke Uzunluğu (km) & km & 2,186 & 2578 \\
\hline V3 & Rapor edilen şebeke Arıza sayısı (adet) & adet & 3,973 & 480 \\
\hline V4 & Rapor edilen Servis Bağlantı Arıza sayısı (adet) & adet & 5,291 & 10020 \\
\hline V5 & Servis Bağlantı Sayısı (adet) & adet & 127138 & 182000 \\
\hline V6 & Tamiri yapılan rapor edilen arıza sayısı (adet) & adet & 7,947 & 10500 \\
\hline V7 & Verisi Doğrulanmış CBS Veri Tabanı olan şebeke uzunluğu (km) & km & 0.00 & 2578 \\
\hline V8 & CBS veritabanı olan ve yeri bilinen vana Sayısı (adet) & adet & 4,066 & 2210 \\
\hline V9 & Toplam vana sayısı (adet) & adet & 4,066 & 2365 \\
\hline V10 & Vana arıza sayısı (adet) & adet & 55 & 150 \\
\hline V11 & Bakım-denetim yapılan vana sayısı (adet) & adet & 93 & 200 \\
\hline V12 & Değiștirilen vana sayısı & adet & 43 & 125 \\
\hline V13 & Şebeke yenilenen bölgede arıza sayısı (adet) & adet & $\mathbf{0 . 0 0}$ & 63 \\
\hline V14 & Şebeke yenilemeden önceki arıza sayısı (adet) & adet & $\mathbf{0 . 0 0}$ & 127 \\
\hline V15 & Rapor Edilmeyen Şebeke arıza sayısı (adet) & adet & $\mathbf{0 . 0 0}$ & $\mathbf{0}$ \\
\hline V16 & Rapor edilmeyen Servis Bağlantı Arıza sayısı (adet) & adet & $\mathbf{0 . 0 0}$ & $\mathbf{0}$ \\
\hline V17 & Yenilenen (yeni yapılan) servis bağlantı sayıs1 (adet) & adet & 210 & 2320 \\
\hline V18 & İdare tarafından yapıllan servis bağlantı sayısı (adet) & adet & 0.00 & 2210 \\
\hline V19 & Rapor edilen arızalara müdahale süresi (saat) & adet & 14,3 & 3 \\
\hline
\end{tabular}

- Çizelge 6. Pilot Sistemler için Performans Gösterge Hesabı

\begin{tabular}{|c|c|c|c|c|}
\hline Kodu & Gösterge Adı & Birim & Sistem 1 & Sistem 2 \\
\hline PG1 & Toplam rapor edilen arıza oranı & arıza/şebeke uzunluğu $(100 \mathrm{~km}) / \mathrm{y} 1 \mathrm{l}$ & 423.85 & 409.55 \\
\hline PG2 & Rapor edilen şebeke arıza oran1 & arıza/şebeke uzunluğu $(100 \mathrm{~km}) / \mathrm{y} 11$ & 181.77 & 18.85 \\
\hline PG3 & Rapor edilen servis bağlantı arıza oran 1 & arıza/şebeke uzunluğu $(100 \mathrm{~km}) / \mathrm{y} 1 \mathrm{l}$ & 242.07 & 390.69 \\
\hline PG4 & Rapor edilen servis bağlantı arıza oranı & arıza/servis bağlantı (1000)/yıl & 308.73 & 50.77 \\
\hline PG5 & Rapor edilen arızalara müdahale verimliği & $\%$ & 85.78 & 100.00 \\
\hline PG6 & Arıza müdahale süresi & saat & 14,30 & 3.00 \\
\hline PG7 & Şebeke veri doğrulama oran1 & $\%$ & Veri Yok & 100.00 \\
\hline \multirow[t]{2}{*}{ PG8 } & Vana Yoğunluğu & vana/şebeke uzunluğu(100km)/yıl & 186.03 & 85.73 \\
\hline & Vana Yoğunluğu & $\%$ & 100.00 & 93.45 \\
\hline PG9 & Vana arıza yoğunluğu & $\%$ & 1.35 & 6.79 \\
\hline PG10 & Vana bakım oranı & $\%$ & 2.29 & 9.05 \\
\hline PG11 & Vana Değişim oran1 & $\%$ & 1.06 & 5.66 \\
\hline PG12 & Yenilenen bölge arıza oran 1 & $\%$ & Veri Yok & 49.61 \\
\hline PG13 & Şebeke Arıza sıklık indeksi & birimsiz & 13.98 & 1.45 \\
\hline PG14 & Servis Bağlantı Arıza sıklık indeksi & birimsiz & 102.91 & 16.92 \\
\hline PG15 & Servis bağlantı yenileme oran 1 & $\%$ & 9.61 & 90.00 \\
\hline PG16 & Servis bağlantı verimliliği & $\%$ & Veri Yok & 95.26 \\
\hline PG17 & $\begin{array}{l}\text { Rapor edilmeyen servis bağlantı arıza } \\
\text { oranı }\end{array}$ & arıza/şebeke uzunluğu $(100 \mathrm{~km}) / \mathrm{y} 1 \mathrm{l}$ & Veri Yok & Veri Yok \\
\hline PG18 & Rapor edilmeyen şebeke arıza oranı & arıza/şebeke uzunluğu $(100 \mathrm{~km}) / \mathrm{y} ı 1$ & Veri Yok & Veri Yok \\
\hline
\end{tabular}


Çizelge 6'da verilen sonuçlar incelendiğinde, her iki sistemde de $100 \mathrm{~km}$ başına toplam arıza oranları yüksek seviyededir. Diğer taraftan, şebekede rapor edilen arıza oranlarına göre, sistem 1 için hesaplanan göstergenin sistem 2'ye göre oldukça fazla olduğu görülmektedir. Sistem 1'de bu oranının yüksek olmasında şebeke yaşı, basınç, boru malzeme kalitesi gibi temel faktörlerin etkili olduğu şeklinde yorum yapılabilir. Benzer şekilde servis bağlantılarındaki arıza oranlarına göre sistem 1 için elde edilen değerin yine çok yüksek olduğu söylenebilir. Bu iki göstergeye göre sistem 1'de bu oranların azaltılması için basınç yönetimi, boru malzeme ve işçilik kalitesinin iyileştirilmesi gibi yöntemler uygulanabilir.

Diğer taraftan sistem 1'de arızaların \% 86'sı onarılırken, sistem 2'de tamamı onarılmış durumdadır. Su, enerji ve finansal verimlilik için bu göstergenin \% 100 olması gerekir. Ayrıca, arızalara müdahale süreleri incelendiğinde, sistem 2 'de süre oldukça iyi düzeyde iken, sistem 1'de ise 14 saat oldukça yüksektir. Bu sürenin artması, sızıntı hacminin artması, abone şikayetlerinin ve su kesintilerinin artması ve hizmet kalitesinin düşmesi anlamı taşımaktadır. Bu nedenle bu sürenin genel olarak 3 ile 5 saat arasında olması önerilir.

Diğer taraftan vanalarla ilgili hesaplanan göstergeler incelendiğinde, PG8 göstergesinin her iki sistemde de \% 100 veya yakın olarak hesaplanmış olması performansın oldukça iyi düzeyde olduğunu ifade etmektedir. Çizelgede PG12 göstergesinin sistem 1 'de veri olmadığı için hesaplanmadığı, sistem 2'de ise oranının oldukça yüksek olduğu görülmektedir. Yeni yapılan bölgede arıza oluşumu genellikle beklenen bir durum değildir. Çizelgede PG17 ve PG18 göstergelerinin hesaplanması için gereken verinin her iki sistemde de olmadığı anlaşılmaktadır. $\mathrm{Bu}$ verileri toplamak için aktif sızıntı kontrolünün planlanması ve sahada uygulanması gerekir.

Son olarak PG13 ve PG14 göstergeleri uluslararası literatürde de yaygın bir şekilde kullanılan arıza sıklık indislerini ifade etmektedir. $\mathrm{Bu}$ gösterge, dağıtım sisteminde $100 \mathrm{~km}$ başına meydana gelen arızaların literatürde önerilen teknik olarak en düşük arıza sayısına oranı şeklinde hesaplanır. Şebeke ana hatlarında $13 \mathrm{ar} ı \mathrm{za} / 100 \mathrm{~km} / \mathrm{y}$ ll gibi teknik olarak en düşük arıza oranı önerilmiştir. Benzer şekilde servis bağlantılarında 3/1000bağlant1/yıl şeklinde en düşük arıza oranı önerilmiştir. PG13 ve PG14 göstergelerinin 1'e yakın olması sistemin iyi bir performansa sahip olduğunu ifade etmektedir. Çizelge incelendiğinde sistem 2 için PG13 oldukça iyi düzeydedir. Ancak bu sistemde PG14 göstergesinin ise oldukça yüksek seviyede olduğu görülmektedir. Diğer taraftan, sistem 1 için PG13 ve PG14 göstergelerinin oldukça yüksek seviyede olduğu görülmektedir.

\section{Sonuç}

$\mathrm{Bu}$ çalışmada dağıtım sistemlerinde meydana gelen arızaların performans göstergelerine göre izlenmesi ve yönetilmesi amaçlanmıştır. Bu kapsamda toplam 18 adet gösterge dikkate alınmıştır. $\mathrm{Bu}$ performans göstergeleri zorluk düzeyleri, gereksinimleri ve veri yapısı dikkate alınarak temel, orta ve ileri seviye şeklinde gruplandırılmıştır. Çalışmada iki pilot sisteme ait veriler kullanılarak analiz yapılmış ve değerlendirilmiştir. Yapılan hesaplamalarda özellikle temel seviye göstergelerin hesaplanmasinda kullanilan veriler her iki sistemde de tutulmaktadır. Ancak özellikle ileri bazı ileri seviye göstergelerin hesabında kullanılan verilerin toplanmasında yaşanan zorluklar nedeniyle hesaplama yapılamamıştır. Dağıtım sistemlerinde ana hat başına veya servis bağlantı başına hesaplanan göstergelerin, şebekenin fiziksel özelliklerini de dikkate almasından dolayı süreç içindeki değişimlerin analiz edilmesinde fayda sağlayacağı düşünülmektedir. Arızaların yönetilmesinde en önemli parametrelerden biri olan arıza onarım süresinin izlenmesi sızıntı hacminin azaltılması için oldukça önemlidir. Örnek hesaplama yapılan sistemlerden, sistem 1 için hesaplanan göstergelerin genellikle düşük performansa sahip olduğu, sistem 2 için hesaplanan göstergelerin ise genel olarak iyi düzeyde olduğu söylenebilir. Özellikle arıza yönetiminde yaygın bir şekilde kullanılan arıza sıklık indislerinin sistem 1'de oldukça yüksek değere sahip olduğu ve iyileştirilmesi gerektiği düşünülmektedir.

Sonuç olarak çalışma kapsamında hesaplanan göstergelerin arıza performansının izlenmesinde referans bilgi üretmektedir. Ayrıca, arızaların azaltılmasında uygulanan yöntemlerden elde edilen kazanımların analiz edilmesinde de bu göstergeler önemli faydalar sağlamaktadır.

\section{Teșekkür}

$\mathrm{Bu}$ çalışma TÜBİTAK (Proje No: 220M091) tarafından desteklenmiştir.

\section{Kaynakça}

Berardi, L., \& Giustolisi, O. (2021). Calibration of Design Models for Leakage Management of Water Distribution Networks'. Water Resources Management 35(8), 2537-51.

Carmona-Paredes, R.B., \& Carmona-Benítez, R.B. (2018). Pressure Management in Water Distribution Systems Using a Self-Tuning Controller to Distribute the Available Potable Water with Equality. Water Resources Management 32(5), 1651-73.

Chik, L., Albrecht, D., \& Kodikara, J. (2017). Estimation of the Short-Term Probability of Failure in Water Mains. Journal of Water Resources Planning and Management. doi:10.1061/(ASCE)WR.1943-5452.0000730.

Cullinane, M. J. (1986). Hydraulic reliability of urban water distribution systems. Proc., Water Forum 1986: World Water Issues in Evolution, ASCE, Reston, VA, 1264-1271.

Diao, K., Zhou, Y., \& Auch, W. (2013). Automated creation of district metered area boundaries in water distribution systems. J Water Resour Plan Manag. 139(2), 184-190.

Eugine, M. (2017). Predictive Leakage Estimation Using the Cumulative Minimum Night Flow Approach. American Journal of Water Resources. 5(1), 1-4.

Farah, E, \& Shahrour, I. (2017). Leakage Detection Using Smart Water System: Combination of Water Balance and Automated Minimum Night Flow. Water Resources Management. 31, 4821-4833.

Fontana, N., Giugni, M., Glielmo, L., Marini, G., \& Zollo, R. (2018). Real-Time Control of Pressure for Leakage Reduction in Water Distribution Network: Field Experiments. Journal of Water Resources Planning and Management. 144(3), doi://10.1061/(ASCE)WR.1943-5452.0000887.

Gheisi, A., Forsyth, M., Naser, G. (2016). Water distribution systems reliability: A review of research literature. Journal of Water Resources Planning and Management 142 (11), 1-13.

Haider, H. (2015). Performance Management Framework for Small to Medium Sized Water Utilities : Conceptualization to Development and Implementation. Civil Engineering. 889900.

Jadhao, R.D., \& Gupta, R. (2018). Calibration of Water Distribution Network of the Ramnagar Zone in Nagpur City Using Online Pressure and Flow Data. Applied Water Science. 8, 29. 
Kutyłowska, M. (2017). Comparison of Two Types of Artificial Neural Networks for Predicting Failure Frequency of Water Conduits. Periodica Polytechnica Civil Engineering. 61(1), 16.

Laucelli, D.B., Simone, A., Berardi, L., \& Giustolisi, O.(2017). Optimal Design of District Metering Areas for the Reduction of Leakages. Journal of Water Resources Planning and Management 143 (6), 04017017.

Marzola, I., Alvisi, S., \& Franchini, M. (2021). 'Analysis of MNF and FAVAD Models for Leakage Characterization by Exploiting Smart-Metered Data: The Case of the Gorino Ferrarese (Fe-Italy) District. Water (Switzerland) 13(5).

Meirelles, L., Brentan, B.M., \& Luvizotto, E. (2018). Optimal Design of Water Supply Networks Using an Energy Recovery Approach. Renewable Energy. 117, 404-413. doi:10.1016/j.renene.2017.10.080.

Moslehi, I., Jalili-Ghazizadeh, M., \& Yousefi-Khoshqalb, E. (2021). Developing a Framework for Leakage Target Setting in Water Distribution Networks from an Economic Perspective. Structure and Infrastructure Engineering 17(6), 821-37.

Mutikanga, H.M., Sharma, S.K., \& Vairavamoorthy, K. (2013). Methods and Tools for Managing Losses in Water Distribution Systems. Journal of Water Resources Planning and Management 139 (2), 166-174.

Nafi, A., Werey, C., \& Llerena, P. (2008). Water Pipe Renewal Using a Multiobjective Optimization Approach. Canadian Journal of Civil Engineering. doi:10.1139/L07-075.

Neamtu, C. (2011). The Use of Water Balance in Determining the Water Loss Strategy. Water Utility Journal. 2, 61-68.

Pietrucha-Urbanik, K. (2015). Failure Analysis and Assessment on the Exemplary Water Supply Network. Engineering Failure Analysis 57, 137-142. doi:10.1016/j.engfailanal.2015.07.036.
Rogers, P.D., \& Grigg, N.S. (2009). Failure Assessment Modeling to Prioritize Water Pipe Renewal: Two Case Studies. Journal of Infrastructure Systems. 15(3), doi:10.1061/(ASCE)10760342(2009)15:3(162).

Roshani, E., \& Filion, Y. (2014). WDS Leakage Management through Pressure Control and Pipes Rehabilitation Using an Optimization Approach. Procedia Engineering 89, 21-28.

Rutger de Graaf, R.B. (2010). Transforming water infrastructure by linking water management and urban renewal in Rotterdam, Technological Forecasting and Social Change, 77(8), 1282-1291.

Salomons, E.,, Skulovich, O., \& Ostfeld, A. (2017). Battle of Water Networks DMAs: Multistage Design Approach. Journal of Water Resources Planning and Management. 143(10), doi:10.1061/(ASCE)WR.1943-5452.0000830.

Tee, K.F., Khan, L.R., Chen, H.P., \& Alani, A.M. (2014). Reliability Based Life Cycle Cost Optimization for Underground Pipeline Networks. Tunnelling and Underground Space Technology. 43, 32-40.

Xu, Q., Qiang, Z., Chen, Q., Liu, K., \& Cao, N. (2018). A Superposed Model for the Pipe Failure Assessment of Water Distribution Networks and Uncertainty Analysis: A Case Study." Water Resources Management. 32 (5), 1713-1723.

Vicente, D. J., Garrote, L., Sánchez, R., \& Santillán, D. (2016). Pressure Management in Water Distribution Systems: Current Status, Proposals, and Future Trends. Journal of Water Resources Planning and Management 142 (2), 1-13.

Wu, Y., Liu, S., Smith, K., \& Wang, X. (2018). Using Correlation between Data from Multiple Monitoring Sensors to Detect Bursts in Water Distribution Systems. Journal of Water Resources Planning and Management. 144(2), doi:10.1061/(ASCE)WR.1943-5452.0000870. 